\title{
Exercise and intervention: On the sociology of powerful knowledge
}

\author{
Jim Hordern* - Bath Spa University, UK
}

\begin{abstract}
This article discusses John White's recent critique of the notion of 'powerful knowledge'. It is argued that White raises some salient points but overlooks the genesis of powerful knowledge as an idea and its debt to Durkheim and Bernstein. It is suggested that the work of Michael Young and others on powerful knowledge can be understood as both an exercise in the sociology of educational knowledge and an intervention in debates about the curriculum. Explicating the relationship between exercise and intervention sheds further light on White's critique and its subject matter.
\end{abstract}

Keywords: sociology of knowledge; curriculum; disciplinarity; concepts

\section{Introduction}

This article reflects on some elements of John White's (2018) critique of the notion of 'powerful knowledge' (PK) in this journal and offers an alternative means of understanding debates about PK that foreground the genesis of the idea and the sociological tradition from which it has emerged. It is argued that the work of Young and others on PK can be seen as both an exercise in the sociology of educational knowledge played out primarily in an academic domain and an intervention within curriculum debates that occur within policy and practice domains as much as in academia. It is suggested that PK should not lose sight of its Durkheimian and Bernsteinian origins or its link to Vygotskian work, and that the sociological argument for PK is primarily about how we understand the relationship between knowledge and society, and therefore takes a socio-historical approach to epistemological questions. Indeed, the approach taken by Young and his collaborators is part of a distinctive tradition, which some philosophers would agree is necessary for a fuller understanding of knowledge. It is argued that PK offers opportunities to see the world differently, and this comes about through social formation of the mind, which is only made possible by and through specialized communities. However, the changing nature of society, and the ever-iterating nature of (always fallible) knowledge, suggests that boundaries between disciplines and between communities must always be semi-permeable and up for debate - and this may have implications for the curriculum.

\section{Comments on John White's arguments}

White (2018: 326) criticizes PK for (inter alia) its reliance on 'sui generis systems of interrelated concepts', a misplaced assumption about the 'gulf between subjectbased and everyday knowledge' (ibid.: 327) and its inadequacy as a starting point for the school curriculum, suggesting that Young is confusing the 'is' and the 'ought' 
(ibid.: 329) by basing his argument for knowledge on 'his empirical observation of schools in their social and historical setting' (ibid.: 329). White also compares the PK debate with earlier debates on Hirst's form of knowledge, arguing that 'discussions of PK lack ... careful exposition and close argumentation' (ibid.: 333-4) and notes that 'writings on powerful knowledge are often a frontier-less amalgam of ideas from many fields' (ibid.: 334). White also recaps some earlier points he has made in criticisms of PK and Young's work (White, 2012), foregrounding his own arguments for an aims-based curriculum.

White (2018: 325) starts his analysis by asking 'what is powerful knowledge (PK)'?, suggesting that the term has a 'strong, positive emotional charge' that may explain 'why it has become attractive to many in the educational world'. He states that 'when we try to see what the term means, the answer is elusive' (ibid.) before using a quote from Young (2015) as a basis for his own interpretation. For White (ibid.: 326), there are 'two main features of PK, epistemological and social', with the epistemological 'to do with bodies of knowledge built around their own, sui generis systems of interrelated concepts' and the social that 'is the province of distinct specialised groups'. While this interpretation could be read from the quote used from Young, it arguably misconstrues the understanding of knowledge that underpins the development of Young's work on PK, namely that the epistemic is inextricable from the social, and vice versa. The two features that White separates for his analysis are seen as mutually constitutive by Young and his collaborators. Their approach is 'socio-epistemic' (Young and Muller, 2013: 233; Muller, 2009: 205), arguing with Durkheim (2001) that contemporary knowledge is a reflection of its socio-historical constitution: it is a product of the ways in which humans have organized themselves to develop symbolic systems to understand the world. It is emergent from (and reliant on) particular forms of social organization that enable specialized knowledge to transcend its original context of production (Young and Muller, 2013). Characteristics of such social organization include 'criterial rules' and 'myriad processes of peer review' (ibid.: 237, 243) that structure interaction and the making of judgements in a disciplinary community. Other authors might supplement this by foregrounding a requirement for 'mutual accountability' and a sense that there is something at stake (Rouse, 2007) that continues to bind participants within the social dynamic, and a commitment to sincerity and accuracy in dealings between participants in the community (Williams, 2002).

White's separation of the epistemological from the social frames the remainder of White's argument. He focuses mainly on the first feature (namely his interpretation of the epistemology of PK) while offering no substantive discussion of the second (the social). This suggests an attempt to drag into epistemology an argument about knowledge that has developed within sociology, and specifically the relationship between knowledge and society (Durkheim, 2001; Bernstein, 2000). It is also important to note that some philosophers have recognized the problems that analytical traditions in philosophy have had with studying knowledge, and have turned towards a more genealogical or socio-historical approach to accompany, or substitute for, more mainstream philosophical inquiry (for example, Bernard Williams (2002), who drew on Nietzsche to develop his approach). As Rorty (2002) notes, Williams sought to highlight 'the changes in the human self-image that have produced our present institutions, intuitions and problems' as a means of exploring the relationship between the quest for truth and the quest for justification. Such approaches enable us to better understand how scientific explanation, and 'ethical and aesthetic judgements' (Young and Muller, 2013: 236) have emerged in the social history of knowledge and led us to where we are today, recognizing the 'integral nature of thought and world' - and that we as 
humans 'mediate existence' (Derry, 2017: 91). Rorty might not have been persuaded by Williams, but he recognized the value of the journey, and the genealogical approach inspired by Nietzsche. As Young and Muller (2013: 236) observe, since debates between Popper and Lakatos in the 1970s, 'epistemic "bestness" distinguishes truth from non-truth in a revisable, non-absolute manner', and therefore a central focus in the study of knowledge becomes how our current understandings of this 'bestness' have been shaped through socio-historical patterns of inquiry (Collins, 2000). As a consequence, the idea that questions of knowledge are purely the province of (pure, analytic) epistemology is highly questionable.

White (2018: 326) draws attention to the different structure of school subjects, critiquing the perceived emphasis in PK on the 'sui generis systems of interrelated concepts'. He contrasts the physical sciences and mathematics, which he says have 'tightly interconnected conceptual schemes', with 'history, geography, English and a foreign language', making a persuasive argument that these latter examples are not in fact built around their own 'system of interrelated concepts' (ibid.). White focuses on examples from the school curriculum in England, a field in which he has particular expertise. However, it is questionable whether PK should necessarily be seen as primarily identifiable by a sui generis system or by a system of interrelated concepts, and it is (for this author) rather important to separate the two aspects of White's characterization here. The term sui generis can be roughly understood as 'in a class of its own' or 'unique', and here it is debatable that this is in fact what Young (2015) is suggesting when he states that PK is systematic, specialized and subject to relatively fixed boundaries. Instead, a more nuanced interpretation could be advanced, suggesting that concepts in any given discipline or subject (for example, geography) could potentially have some origin in another discipline or subject (for example, sociology or economics) but that these concepts have been delocated from their original disciplinary context and relocated (Bernstein, 2000) in the new disciplinary context while undergoing some transformation to fit the conceptual schema of the receiving discipline and its 'supervening purpose' (Muller, 2009: 213). In the process of 'selection, appropriation and transformation' the concepts may lose some of their power or some reference to the debates through which they emerged (Hordern, 2014). Arguably, it is the job of the receiving discipline to capture some essence of those original debates within the new disciplinary context and the curriculum that results from it. There is always a risk that certain concepts (for example, from sociology or economics) acquire particular prominence if recontextualized into another subject (for example, geography) while other related concepts, or alternative disciplinary perspectives, do not.

However, White's spotlight on 'systems of interrelated concepts' as a feature of PK raises important questions about what is meant by PK in different subjects. In attempts to convey the essence of the argument about PK there is a risk of oversimplifying the varied and diverse elements that might make up a school subject. Instead of focusing only on interrelated concepts (which as White argues may not be the most prominent and defining features of any given subject), PK needs a broader understanding that deals with the various (interrelated) elements that make up knowledge and expertise. Winch (2010) offers a way into this, by discussing not only propositional knowledge, but also the capacity to infer between propositions, the capacity to recognize and apply procedures to evaluate new knowledge claims, and various aspects of knowledge by acquaintance. Highly significantly for this debate, Winch also draws attention to normative versions of practice as a basis for establishing and iterating expertise. If we follow Winch, we might argue that a subject such as history is defined as much by its procedures and the capacity that historians have to make inferences from propositions 
(that is, building their 'specifically historical knowledge', as White (2018: 327) suggests), rather than a web of interrelated abstract concepts per se. Developing historical consciousness or a sense of historical significance (Seixas, 2017) may be particularly important in becoming a historian, just as developing a sociological imagination (Wright Mills, 1959) is central for the sociologist. However, gaining high levels of expertise is likely to require sustained engagement in the practice of the discipline. In his article on vertical and horizontal discourses, Bernstein (2000) suggests a related argument we need to focus on discourses and not just knowledge structures to get a handle on what PK means, and therefore take account of the distinct yet related specialized social practices from which the knowledge structures are inextricable (Muller, 2014).

White also focuses on the errors of what he perceives to be a 'gulf between subject-based and everyday knowledge' (White, 2018: 327) in Young's work. However, it is again debatable whether Young (and his collaborators) emphasize this gulf. What they argue for is a differentiation between the specialized and the everyday based on the needs and aspirations of human societies (Young and Muller, 2013), but the use of the word gulf implies a separation and hard boundary which does not quite resonate with Young and Muller's (2010: 16) focus on 'boundary maintenance' as a means to 'boundary crossing' in PK. Gamble (2014) illustrates, through a discussion of craft and mathematics pedagogy that draws on Vygotsky and Bernstein, the processes by which objects and interactions can become sacred (or specialized) within pedagogical contexts. Through a course of induction, students learn to 'cross the boundary' into a context governed by the 'symbolic', while 'everyday objects are introduced into the classroom' and thus 'stripped of their context-specificity to acquire symbolic meaning' (Gamble, 2014: 66). A student already inducted into the specialized practice (of maths or furniture-making) will more easily see the object for its significance to the specialized practice (while still also being able to see it for its everyday meaning), while a novice will be unable to do this.

This example brings out how proximate our notions of the specialized and everyday may be and offers the possibility for a reinterpretation of some of White's illustrations of the relationship between them. For example, White (2018: 326) suggests that everyday knowledge 'depends on networks or interrelated concepts (think perhaps of "chair" and "furniture"), but children learn how to use these outside school'. While he may be right that children learn what a chair is at home, and may well learn the relationship between 'chair' and its membership of the category 'furniture', this does not mean that there is not a more specialized (or powerful) understanding of what a chair is, and indeed of types of furniture. As Gamble's (2014) work illustrates, there is an organized and systematic way of understanding the design and construction of furniture based on 'visualizing' the relationship between parts and whole, and this body of knowledge is inextricable from the skilled practitioners who are intimately involved in its practice. The existence of an everyday understanding (of an object, context or phenomenon) does not preclude the existence of a specialized understanding (of the same object, context or phenomenon). And the distinctions between the two are not static; they are in a constant train of iteration, pulled in different directions by the requirements of our contemporary societies (Durkheim, 2001; Bernstein, 2000; Young and Muller, 2013).

Indeed, the acquisition of PK (or engagement within a disciplinary community committed to husbanding and iterating PK) may be more about seeing the world differently or acquiring a specialized lens through participation in a socio-epistemic community, than about specifically learning a bedrock of interrelated concepts, although that may be particularly important in some subjects. Arguably this also raises 
questions about the ways in which we acquire understanding and participate with others in order to learn knowledge in different subjects (Sfard, 1998). In some subjects it is participation in certain activities that may be particularly important for attaining proficiency (for example, dance, which Young raises in contrast to maths, as White notes (2018: 326)), while in others the full participation (for example, in a philosophical or sociological debate, or when solving maths problems) may be predicated on a command of certain concepts and the capacity to infer between propositions. Induction into specialized knowledge does not necessarily need to start in an institution, however, as White (2018) illustrates in his comment on Reiss's experience of learning maths. Specialized knowledge is also out there in the world, embedded in some of our practices and everyday activities, often without our acknowledgement (Hordern, 2018). Nevertheless, there may be a limit to which PK can be attained without forms of pedagogical participation.

White's argument is rooted firmly in debates about the school curriculum in England, and this is understandable given his interest and expertise in this area and the impact that PK has started to have on specific curriculum debates. However, the frame within which he locates his argument conjures a particular version of the PK argument that loses some of the wider hinterland from which the notion has emerged, as has been outlined above. There are further problems with locating debates about PK only in the school curriculum world, as arguably an understanding of PK requires a focus on knowledge production in disciplines, as much as the ordering of knowledge in the curriculum (Muller, 2009; Young and Muller, 2010, 2013). Bernstein's (2000) work, to which PK is indebted, is helpful here, in distinguishing between the field of knowledge production and the field of knowledge recontextualization (in which the curriculum emerges). What Bernstein separated analytically in the pedagogic device were the dynamics through which knowledge becomes organized into a disciplinary form, on the one hand, and the dynamics within which knowledge became organized into the curriculum, on the other hand. As Bernstein was largely focused on arguments about the school curriculum and its pedagogization, with the exception of some elements of his last book, there was much discussion in his work of the dynamics of curriculum formation. However, the PK work that Young and his collaborators have engaged in has not only intervened in debates about the curriculum (that is, in Bernstein's recontextualization field), but has also focused on knowledge production in education and beyond (that is, in Bernstein's production field), including in work on the constitution of professional knowledge and on knowledge in higher education (Young and Muller, 2014; Muller, 2009). This has been necessary as part of the broader project of which PK is a part, because (as White notes but does not discuss in depth) PK is rooted in an understanding of the importance of 'distinct specialised groups' (White, 2018: 326), and such groups usually necessitate considerable involvement from higher education, including when they are mainly concerned with the school curriculum (for example, geographical or historical subject associations).

And yet the argument that PK makes for the relationship between higher education and the school curriculum is not to be found in White's critique. The sense that knowledge is ever-changing, iterating and provisional runs through Young's work on the sociology of knowledge. For Young and Muller (2013: 236), truth is always considered to be 'revisable' and 'non absolute' as a consequence of disciplinary dynamics, and arguably this is just as important as (or more important than) the elements that White chooses to discuss. While White again may have a point in suggesting that Young is reluctant to engage with 'ought' questions, in order to justify knowledge as a basis for the curriculum as opposed to aims, this reluctance can be understood 
through recourse to the sociological approach to the constitution of knowledge and its inbuilt fallibilism. Young appears to accept that without a better option (and remaining cognizant of the risks of starting with aims), it is better to fall back on the changing nature of the shape of knowledge production in higher education as a guide to what should be in the curriculum, within the context of the 'relative stability of subjects and their boundaries' (Young, 2012 in White, 2018: 329). Nonetheless, it is possible that a compromise could emerge on these positions. The 'ethical investigation' that White (2018: 329) calls for could usefully examine the ethics and practices of disciplinarity and mutual accountability that arguably underpin the PK thesis, which in their ideal form might not be too different from enabling 'students to lead flourishing lives themselves' and helping 'others to do so'.

\section{Better understanding PK as exercise and intervention}

While White's arguments have raised a series of salient points, it is argued here that to better understand PK we need to secure a better grasp of the sociology of PK, and therefore in particular the different dynamics of the communities into which the notion has been introduced. It is possible to share some of White's reservations about PK's 'strong, positive, emotional charge', while finding much of the hinterland to the notion, persuasive and highly significant in terms of how we understand the relationship between knowledge and society. More than anything, it is important to note that a notion such as PK may be taken beyond the bounds of academia and used by various organizations and actors to intervene in the worlds of policy and practice for reasons that have little to do with the original notion. This is an issue that has particular resonance in a discipline (or field) such as education, with its orientations towards practice and occupational preparation, and its inevitably political character (Hordern, 2018).

To better understand PK, I suggest we need to draw a semi-permeable boundary between the arguments of Young and his collaborators about the sociology of educational knowledge, which I contend is a primarily academic exercise, and the arguments of Young and others that are interventions in debates about the curriculum in national (and in some cases supranational contexts), and therefore interface to a much greater extent with the substance of policy and practice. It is interesting to note that Guile et al. (2017) in the recent Festschrift for Young, chose to distinguish between Young's contributions to sociology (the first part) and the curriculum (second part), while leaving the third part to professional and vocational education. Young and Muller (2013: 229) themselves make a distinction between PK as a 'sociological concept' and as 'a curriculum principle'. The most important thing for the present discussion is that the communities within which the exercise and the intervention are undertaken are fundamentally different. While the exercise has played out in academic communities constituted to withstand the subtleties and nuances of debates about the sociology of knowledge in education, the intervention has resulted in opportunities for the notion of PK to be simplified, misunderstood and put to use for political purposes, because it has played out in policy (and practice) communities that have offered the notion prominence but do not operate with an academic dynamic. The policy communities do not necessarily take into account the criterial rules to which Young and Muller (2013) draw attention. Furthermore, 'mutual accountability', if it ever existed, has largely disappeared, and sincerity and accuracy (Williams, 2002) are not always priorities when political imperatives come into play. 
The academic exercise discussing the sociology of educational knowledge has offered the opportunity for Young to (largely, but perhaps not entirely) reverse his position on knowledge and society through a rereading of Bernstein, Durkheim and Vygotsky, and to collaborate with some of his erstwhile critics (notably Rob Moore and Johan Muller) to strengthen and undergird a conceptual position. This work resulted in articles which sketched out and developed an academically robust position (Moore and Young, 2001; Young, 2008). PK has therefore emerged from a body of work that seeks to develop a sociology of knowledge that 'stands in contrast to more traditional sociologies of knowledge which have tended to associate the sociality of knowledge with bias' (Young and Muller, 2013: 230). This academic work 'emphasises how the sociality of knowledge underpins its emergent "objective" character' (ibid.: 230) and therefore resists relativism or approaches to knowledge which simply focus on the power of the knower. The exercise has been bolstered by symposia organized by Young, Muller, Rob Moore and others at the University of Cambridge, which have had the aim of exploring 'access for all to cognitively powerful forms of knowledge as a principle of social justice' and have involved academics 'informed by the family of traditions, such as social realism and Bernsteinian studies, which have established this as a primary focus' (CSKE, 2016).

However, the intervention in curriculum debates has enabled new interpretations and manifestations of PK to emerge that may not reflect all the intentions of its originators. Equated with socially refined forms of knowledge (DfE, 2011) in the National Curriculum Review, the PK notion has surfaced in the policy domain, and thus has become part of the debates about curriculum practice that involve school leaders and teachers in England. The realities of curriculum reform processes in England, and in particular the centralized and government-controlled form of curriculum policymaking, mean that decisions have to be made by policymakers and school leaders about the actual knowledge authorized as powerful. In DfE (2011: 6) for example, PK becomes conflated with essential knowledge that is expressed in terms of facts, concepts, principles and fundamental operations in curriculum documentation. Tim Oates, the Chair of the Expert Panel of the 2011 National Curriculum Review, in his chapter in Young's Festschrift, goes as far as to suggest that Young and Muller's (2010) Future 3 Curriculum (equating to PK) is not too dissimilar to a Future 1 Curriculum (which Young and Muller (2010: 17) describe as 'overt' and 'strictly stipulated' and 'a recipe for social divisiveness, inequality, unhappiness, and conflict'). ${ }^{1}$ According to Oates (2017: 159), there is no substantive division because both have a preference for subjects first and foremost and just require 'a short and intensive debate to resolve the practicalities of translation into legitimate curriculum policy'. However, Young and Muller's Future 2 (which values 'progressive pedagogy' and the 'end of boundaries' (2010: 19) with the aim of achieving learner autonomy and equality of access) 'in epistemological terms is in a galaxy far, far away' (Oates, 2017). Guile et al. (2017), in their summary of Oates's chapter in the Festschrift, interpret this as an argument for seeing Future 2 as the real villain of the curriculum world.

For others, too, it is a subject-based curriculum which is the real goal, not the nuances and potential uncertainties of PK. Alex Standish's (a contributor to the Institute of Ideas (lol, 2012)) response to the National Curriculum Review, asserts that 'following the decline of traditional conservative justifications for a subject-based education over recent decades, current policymakers lack any strong rationale for why subject should be taught in schools' (ibid.: 8). But Oates's position (and perhaps that of Standish) neglects the fact that Future 3 PK wouldn't exist without the debates that underpinned the development of Future 2 (and the concerns of those that advocate Future 2 as a 
response to Future 1). It is interesting to read further in the Institute of Ideas education forum report and see contributors describing PK as 'vague' and showing evidence of 'posturing' (ibid.: 11 and 16). For some, PK may be useful for garnering academic credibility for their real objectives, to be dismissed when no longer deemed necessary.

Is there a risk of a (partial) hijacking of PK by groups with particular motives who have little time or interest in the nuances of academic debates? It is possible that it could be seen in that way. In the English context, where there are assertions that school leaders and teachers have an 'appetite' for evidence 'presented crisply and cleanly, stripped of academic jargon, to inform their decision-making' (EEF, 2018: 2), a reductive interpretation of PK could be used as part of an advocacy for a top-down curriculum focused on 'core subjects' that can support school effectiveness and improvement agendas, narrowly conceived. If leaders and teachers are being pushed into taking decisions by a schooling system that treats schools as functional agents of policy implementation and teachers as instrumental technicians, then there may be little choice or debate about knowledge (Hordern and Tatto, 2018). The appetite for knowledge may be there, but the social organization of knowledge in the policy and practice domains can lead to a force-feeding of a particular (potentially poisonous) sustenance. Such an interpretation suggests that the 'knowledge-led professionalism' with 'teachers as "curriculum leaders"' that Lambert (2017: 141) advocates will remain difficult to orchestrate in many contexts. There may be little to gain for children in a subject-based curriculum if the resultant pedagogy does not take their circumstances and starting points fully into account (Whitty, 2010), and if teachers are not in a position to make this (pedagogically) possible as a consequence of overstipulation, or pressure from school leaders to meet certain narrow objectives.

PK has thus taken root not solely as an academic notion (as is perhaps best illustrated in Young and Muller, 2013), but as an idea that has influenced policy thinking and curriculum reform and has proved appealing to overtly political organizations (such as the Institute of Ideas, 2012). The relatively cordial and forgiving atmosphere of academia is rather different from the policy world: the specialized disciplinary community is absent and no longer able to uphold the 'mutual accountability', 'sincerity' or 'accuracy' which we would hope for (if not always obtain) in academic circles. This is of course a pattern not unique to PK, but could occur with any academic notion that has resonance beyond academia and becomes a popular idea. It could nevertheless be argued that PK has helped reinvigorate debate about the curriculum that will always cross boundaries between schools, education academics and policymakers. The longer-term consequences may be beneficial for curriculum-thinking and curriculummaking, even if the PK curriculum (as interpreted by some) is not the end point.

However, the relative prominence of the intervention in curriculum debates as opposed to the academic exercise of adumbrating the hinterland of PK has other consequences, which have become apparent in some of the writings of both academics and other interested parties about PK; these are reflected somewhat in White's (2018) critique. In particular, there may be tendencies to overlook the relationship between knowledge production and the school curriculum (and the need for an understanding of a recontextualization process between discipline and subject); to focus specifically on concepts and knowledge structures, as opposed to thinking more broadly about the varied dimensions of knowledge; and to understand PK simplistically as ammunition to reinforce a particular version of the subject curriculum. Furthermore, and this is not specifically elaborated in White's critique, there is also a risk that PK becomes conflated with particular forms of pedagogy (Whitty, 2010), and to justify what some would consider a traditional, almost authoritarian, approach to schooling. 
White's arguments can therefore be seen as part of a necessary response and challenge to the PK intervention in curriculum debates. A number of the questions raised are pertinent and substantive, but can perhaps be better understood if we grasp the origins of the PK ideas and the arguments from which they emerge. White's (2018: 333-4) criticism that debates about PK lack 'careful exposition and close argumentation' holds true only for the intervention in curriculum discussions. He would be right that these discussions do not meet standards of 'sincerity' and 'accuracy', to use Williams's (2002) terms. His charge does not, however, hold so well for the academic exercise that preceded and continues to run alongside the curriculum intervention and manifestations of PK (for example, Young and Muller, 2013). Those academic debates can be understood as part and parcel of discourse in the sociology of knowledge, drawing where necessary on philosophical and historical sources, just as philosophy itself has admitted that it may need to reach beyond its boundaries and draw on sociology and history to tackle questions of knowledge in the round (Williams, 2002; Rorty, 2002).

\section{Concluding remarks}

This article has asserted that PK cannot be fully grasped without an understanding of its sociological hinterland. PK emerges from a tradition which understands knowledge as socio-historically constituted, in which the social and the epistemic are inextricable, and where certain kinds of social relations are necessary for sacred (or powerful) knowledge to arise and for its power to be sustained. Bernstein's (2000) work elaborates the Durkheimian distinction between the sacred and the profane and demonstrates its analytical potential, while Young and Muller (2013) and others articulate Durkheim and Bernstein's work with further philosophical, sociological and educational thought, and explore implications for the curriculum; and this has led to PK. But there are considerable risks of misinterpretation if this subtle socio-epistemic hinterland of PK is not understood or if it is wilfully ignored. The 'positive emotional charge' (White, 2018: 325) of PK makes it potentially useful political ammunition - and therefore it may be used in a variety of ways for rather different purposes, including to justify conservative or culturally elite curriculum prescriptions.

Foregrounding the academic exercise that led to PK also suggests that it may be important to continue this academic work to further develop PK or related ideas such as specialized knowledge (a term that has less of the emotional resonance of PK). Here, I briefly suggest two related ways in which this could be done to enhance understandings about PK in disciplines and the curriculum.

The first is to pick up the earlier point about normative practice as an underpinning for the specialized disciplinary communities and the socio-epistemic dynamic which produces specialized or powerful knowledge. Rouse (2007) writes that normative definitions of practice rest on notions of 'mutual accountability' between practitioners and a sense that there is something 'at stake'. Winch (2010), in a similar vein, identifies the necessity for normative evaluation in any expert practice, and for the constitution of norms to be a social process in which practitioners' participation and understanding is key. Arguably, there is some articulation here with Durkheimian notions of social organization (Hordern, 2018), just as there are with understandings of disciplinarity in the philosophy of education (Bridges, 2006). Young and Muller's (2013) work touches on this, and there could be further exploration of how norms might be constituted, which might be different in different disciplines and subject communities depending on their orientations (that is, to particular forms of practice, occupation or 
subject matter). And the practice idiom has more to offer, in particular to explicate (for example, drawing on Vygotskian work) the ways in which novice practitioners become experts through particular forms of participation with others.

The second is to step back and reflect more on the relationship between aims and knowledge as a basis for the curriculum, and to ask if these approaches are really mutually exclusive, as the debates between Young and White could lead us to believe. One reading of Young's work might suggest that the aims that guide the ongoing iteration of disciplines and disciplinary communities could be useful for thinking about the curriculum, particularly when arguments return to Bernstein's idea that knowledge enables citizens to engage in 'society's conversation about itself' (Young and Muller, 2013: 245). A source for a discussion about aims could be Bernstein's (2000) pedagogic rights, which foreground participation, inclusion and enhancement, particularly if these are seen as having mutually reinforcing capacities. However, in order to gather and gain support for a set of aims which adequately represent the relationship between knowledge and society, disciplines and curricula, there needs to be a fuller recognition of the extent to which all voices (with particular support to the new voices) need to be included and enabled to participate in our contemporary societies. On the one hand, a PK that does not explicate and reflexively re-examine its aims risks retreating into conservatism and stasis, and becoming seen as representative of particular social groups. On the other hand, a PK that sees itself as constantly iterating to engage with the character and needs of all in society will need to debate the aims that lie behind and within it, and to do this it will need the kinds of academic exercises that Young and his collaborators have engaged in, not just interventions in the curriculum.

\section{Acknowledgements}

The author is grateful to the two anonymous reviewers for their comments on this article during the review process, which have helped improve the clarity of the argument.

\section{Notes on the contributor}

Jim Hordern is Reader in Educational Studies at Bath Spa University, and has previously worked at the Institute of Education (IOE) and at the University of Bath. His research interests are in educational knowledge and practice, and he is Book Reviews Editor of the Journal of Vocational Education and Training (JVET).

\section{Note}

1 Young and Muller (2010: 20) introduced 'three educational scenarios for the future': Future 1 , which prioritizes 'transmitting elite cultural knowledge to the select few' (ibid.: 16-17); Future 2, which weakens knowledge boundaries and integrates subjects; and Future 3, which recognizes that specialized or powerful knowledge is produced in certain social conditions and leads to 'preferred curriculum and pedagogic models' (ibid.: 20).

\section{References}

Bernstein, B. (2000) Pedagogy, Symbolic Control and Identity: Theory, research, critique. Rev. ed. Lanham, MD: Rowman \& Littlefield.

Bridges, D. (2006) 'The disciplines and discipline of educational research'. Journal of Philosophy of Education, 40 (2), 259-72.

Collins, R. (2000) The Sociology of Philosophies: A global theory of intellectual change. Cambridge, MA: Harvard University Press. 
CSKE (Cambridge Symposium on Knowledge in Education) (2016) 'The Fourth Cambridge Symposium on Knowledge in Education: Call for papers'. Online. https://cske17.wordpress. com/2017-the-fourth-symposium/ (accessed 26 July 2018).

Derry, J. (2017) 'What is educationally worthwhile knowledge? Revisiting the case for powerful knowledge'. In Guile, D., Lambert, D. and Reiss, M.J. (eds) Sociology, Curriculum Studies and Professional Knowledge: New perspectives on the work of Michael Young. London: Routledge, 84-96.

DfE (Department for Education) (2011) The Framework for the National Curriculum: A report by the Expert Panel for the National Curriculum review. London: Department for Education.

Durkheim, É. (2001) The Elementary Forms of Religious Life. Trans. Cosman, C. Oxford: Oxford University Press.

EEF (Education Endowment Foundation) (2018) Annual Report 2017. London: Education Endowment Foundation. Online. https://tinyurl.com/y96cco8k (accessed 17 November 2018).

Gamble, J. (2014) '"Approaching the sacred": Directionality in the relation between curriculum and knowledge structure'. British Journal of Sociology of Education, 35 (1), 56-72.

Guile, D., Lambert, D. and Reiss, M.J. (2017) 'Consistency, contradiction and ceaseless enquiry in the work of Michael Young'. In Guile, D., Lambert, D. and Reiss, M.J. (eds) Sociology, Curriculum Studies and Professional Knowledge: New perspectives on the work of Michael Young. London: Routledge, 1-14.

Hordern, J. (2014) 'How is vocational knowledge recontextualised?'. Journal of Vocational Education and Training, 66 (1), 22-38.

Hordern, J. (2018) 'Educational knowledge: Traditions of inquiry, specialisation and practice'. Pedagogy, Culture and Society, 26 (4), 577-91.

Hordern, J. and Tatto, M.T. (2018) 'Conceptions of teaching and educational knowledge requirements'. Oxford Review of Education, 44 (6), 686-701.

Iol (Institute of Ideas) (2012) Towards a Subject-Based Curriculum: A policy response from the lol's Education Forum. London: Institute of Ideas.

Lambert, D. (2017) 'The road to Future 3: The case of geography'. In Guile, D., Lambert, D. and Reiss, M.J. (eds) Sociology, Curriculum Studies and Professional Knowledge: New perspectives on the work of Michael Young. London: Routledge, 132-45.

Moore, R. and Young, M. (2001) 'Knowledge and the curriculum in the sociology of education: Towards a reconceptualisation'. British Journal of Sociology of Education, 22 (4), 445-61.

Muller, J. (2009) 'Forms of knowledge and curriculum coherence'. Journal of Education and Work, 22 (3), 205-26.

Muller, J. (2014) 'Every picture tells a story: Epistemological access and knowledge'. Education as Change, 18 (2), 255-69.

Oates, T. (2017) 'Powerful knowledge - moving us all forwards or backwards?'. In Guile, D., Lambert, D. and Reiss, M.J. (eds) Sociology, Curriculum Studies and Professional Knowledge: New perspectives on the work of Michael Young. London: Routledge, 157-68.

Rorty, R. (2002) 'To the sunlit uplands'. London Review of Books, 24 (21), 13-15. Online. https://tinyurl.com/y724jgfz (accessed 17 November 2018).

Rouse, J. (2007) 'Social practices and normativity'. Philosophy of the Social Sciences, 37 (1), 46-56.

Seixas, P. (2017) 'A model of historical thinking'. Educational Philosophy and Theory, 49 (6), 593-605.

Sfard, A. (1998) 'On two metaphors for learning and the dangers of choosing just one'. Educational Researcher, 27 (2), 4-13.

White, J. (2012) 'Powerful knowledge: Too weak a prop for the traditional curriculum?'. New Visions for Education Group, 14 May. Online. https://tinyurl.com/yarhefgo (accessed 17 November 2018)

White, J. (2018) 'The weakness of "powerful knowledge"'. London Review of Education, 16 (2), 325-35.

Whitty, G. (2010) 'Revisiting school knowledge: Some sociological perspectives on new school curricula'. European Journal of Education, 45 (1), 28-45.

Williams, B. (2002) Truth and Truthfulness: An essay in genealogy. Princeton: Princeton University Press.

Winch, C. (2010) Dimensions of Expertise: A conceptual exploration of vocational knowledge. London: Continuum.

Wright Mills, C. (1959) The Sociological Imagination. New York: Oxford University Press.

Young, M. (2008) Bringing Knowledge Back In: From social constructivism to social realism in the sociology of education. London: Routledge.

Young, M. (2015) 'Unleashing the power of knowledge for all'. Spiked, 1 September. Online. https://tinyurl.com/y9no2wgh (accessed 17 November 2018). 
Young, M. and Muller, J. (2010) 'Three educational scenarios for the future: Lessons from the sociology of knowledge'. European Journal of Education, 45 (1), 11-27.

Young, M. and Muller, J. (2013) 'On the powers of powerful knowledge'. Review of Education, 1 (3), 229-50.

Young, M. and Muller, J. (eds) (2014) Knowledge, Expertise and the Professions. London: Routledge. 